\title{
Far Lateral Transcondylar Approach for Anterior Foramen Magnum Lesions
}

\author{
WAQAS MEHDI ${ }^{1}$, AZAM NIAZ ${ }^{1}$, MUHAMMAD IRFAN ${ }^{2}$ \\ SHAHZAIB TASDIQUE ${ }^{\mathbf{1}}$, SAMRA MAJEED ${ }^{3}$ \\ Departments of Neurosurgery, ${ }^{1}$ Mayo Hospital, ${ }^{2}$ PINS, Lahore General Hospital, \\ ${ }^{3}$ Services Hospital, Lahore - Pakistan
}

DOI: $10.36552 /$ pjns.v24i2.454

\begin{abstract}
Objective: To study the efficacy and safety of far-lateral transcondylar approach for anterior foramen magnum lesions with early experience at our Institute.

Material and Methods: We treated six patients, with lesion anterior to the foramen magnum and posterior to the brainstem and cervical cord in a period of 2 years, March 2017 to March 2018.Initial assessment was made by history and examination followed by CT scan and contrast MRI. All were treated using far-lateral transcondylar approach.
\end{abstract}

Result: Among six patients, there were two were male and four were female. Three of these patients had a meningioma while two patients had neurofibromas and one clival chordoma. Total excision was achieved in five neoplastic cases, while subtotal excision was done in one case. There were no fresh postoperative deficits in any of the other patients. One patient had an unexplained sudden cardiorespiratory arrest 18h after the surgery and succumbed. One patient had cerebrospinal fluid (CSF) discharge from the wound, which was satisfactorily managed by lumber CSF drainage.

Conclusion: This approach provides an excellent approach to lesions located anterior to foramen magnum posterior to the brainstem and upper cervical cord. Gross total excision of these benign and malignant lesions is safely possible through this approach.

Keywords: Craniovertebral Junction, Far-Lateral Transcondylar Approach, Anterior Foramen Magnum, Brain Stem, Chordoma.

\section{INTRODUCTION}

The anterior foramen magnum and craniocervical junction is a site for various neoplastic lesions such as meningioma, chordoma, epidermoid, neurofibroma, and vascular lesions such as a vertebral artery (VA) aneurysm. Initial surgical treatment of these pathologies was fraught with many complications and incomplete removal due to the proximity of important neurovascular structures. ${ }^{1-3}$ However, development of lateral approaches has provided excellent exposure and access to these lesions resulting in complete excision of these lesions and reduced the frequency of unwanted complications. We presented the short series of six patients whom we treated using the far-lateral approach with excellent results in majority patients.

Far lateral transcondylar approach is an excellent approach with good surgical excision or debulking of anteriorly placed foramen magnum lesions. The morbidity and mortality of this approach is much less than conventional posterior midline approach. Better orientation of approach makes it easier to prevent unwanted complications.

Anterior foramen magnum region is apparently horrifying region for neurosurgeons. Related complex and important neurovascular structures make it very sensitive region. Complex benign or malignant lesions 
in this region are diagnosed clinically and radiologically. Various benign and malignant pathologies can be present in this region like meningiomas, neurofibroma, epidermoid, neurenteric cyst, chordomas, aneurysms, brainstem Gliomas etc. Their surgical resection is important with the preservation of anatomical structures. By understanding the anatomy and stability of craniocervical junction the far lateral Transcondylar approach definitely helped in achieving the target of surgical excision or debunking of anterior foramen magnum region. The results were much better than the conventional posterior midline approach.

\section{MATERIAL AND METHODS}

\section{Study Design}

Prospective observational study.

\section{Inclusion Criteria}

We treated six patients (Table 1) two males and four females, with lesion anterior to the foramen magnum, posterior to the brainstem and cervical cord.

\section{Exclusion Criteria}

Previously operated cases, patients with multiple comorbidities and who refused concent.

\section{Data Collection}

Prior informed consent was taken from the patients and relatives regarding surgery and use of their data for research activities including scientific publications.

\section{Surgical Technique}

The operative technique adopted by us is described below.

\section{Position}

We used a modified park-bench position (Figure 1). The patient was placed in the lateral position and supported with side supports, straps, and adhesive plaster so that the body is held tightly during any sideward tilt of the table if required. The opposite arm was dropped and positioned, padded adequately and fixed to the horizontal bar of the Mayfield Head Frame. The head was flexed, rotated, and laterally flexed by around 30 degrees to the opposite side so that the mastoid is at the highest position.

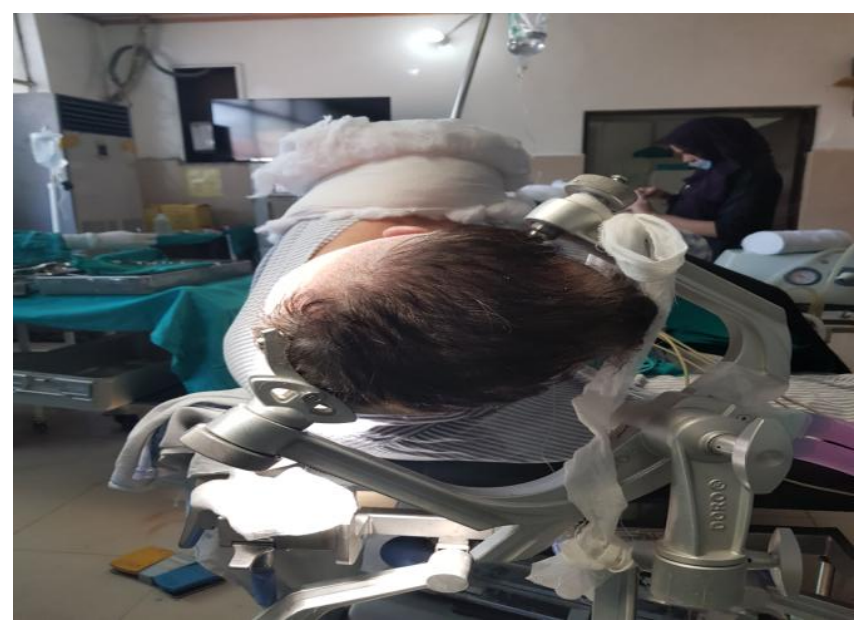

Fig. 1: Patient Positioning in Mayfield head Clamp (photograph used with permission).

\section{Incision}

The side of the approach was dictated by the lateral extension of the lesion. We used a retroauricular curvilinear incision starting 4-5 cm above and behind the pinna and continued inferiorly to the neck over the posterior border of the sternocleidomastoid muscle to the level of C3 or C4 (Figure 2).

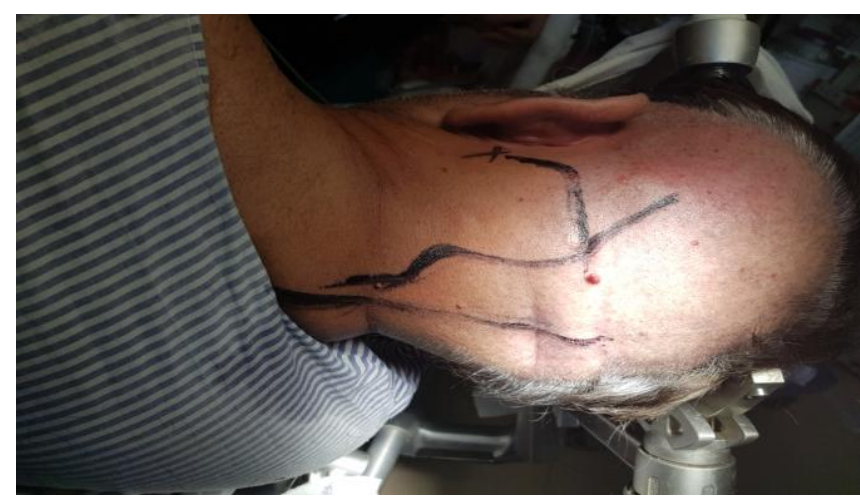

Fig. 2: Incision markings (photograph used with permission).

\section{Muscle Exposure}

The first superficial layer consists of the trapezius and sternocleidomastoid. The middle layer consists of splenius capitis, longissimus capitis, and semispinalis capitis. Both these layers were incised, detached, and reflected as a single layer, and the suboccipital triangle was exposed. This triangle, the third layer, consists of the rectus capitis posterior major medially, inferior oblique inferiorly, and superior oblique superolaterally. Both the oblique muscles were 
attached to the $\mathrm{C} 1$ transverse process laterally; medially, the inferior oblique was attached to the $\mathrm{C} 2$ spinous process, while the superior oblique was attached to the temporo-occipital suture.

\section{Exposure of the Vertebral Artery}

Exposure and control of the extradural VA are an important step in this approach. This was achieved by identifying the VA from its exit at the $\mathrm{C} 2$ foramen transversarium, between $\mathrm{C} 2-\mathrm{C} 1$ foramina, exit from $\mathrm{C} 1$ foramen, and over the $\mathrm{C} 1$ lateral mass vertebral groove to enter the dura mater. Some small branches from the VA to the adjacent muscles may be sacrificed.

\section{Bone Exposure}

A lateral suboccipital craniectomy was performed followed by hemilaminectomy of $\mathrm{C} 1$. The extent of the suboccipital craniectomy medially and superiorly depends on the extent of the lesion and the exposure required. The transverse-sigmoid junction may also be exposed if required. If further inferior exposure is required, hemilaminectomy of $\mathrm{C} 2$ and $\mathrm{C} 3$ may be done depending on the extent of the lesion. The posterior $30 \%-40 \%$ of the occipital condyle was drilled extradurally. This step helped in the angle of exposure and greater visualization of the ventral and ventrolateral aspect of the $\mathrm{CV}$ junction. In no instance, the VA was transposed (Figure 3).

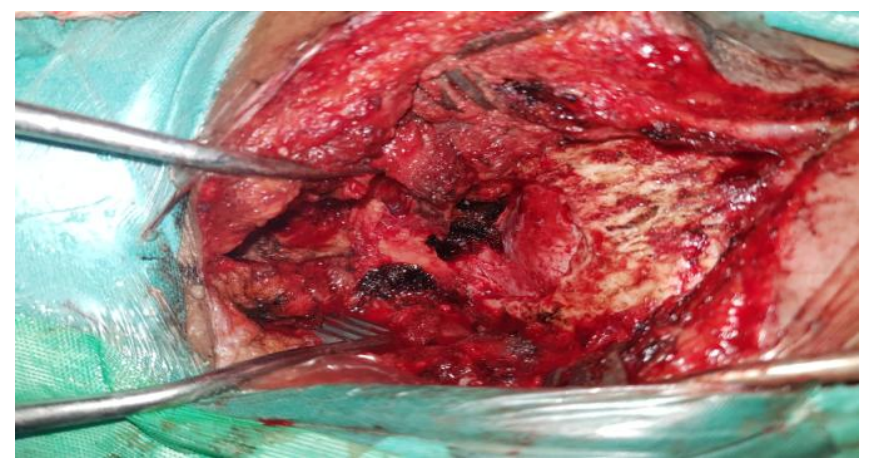

Fig. 3: Bony Exposure.

\section{Dural Opening}

The dura was opened in a slightly curvilinear fashion (Figure 4).

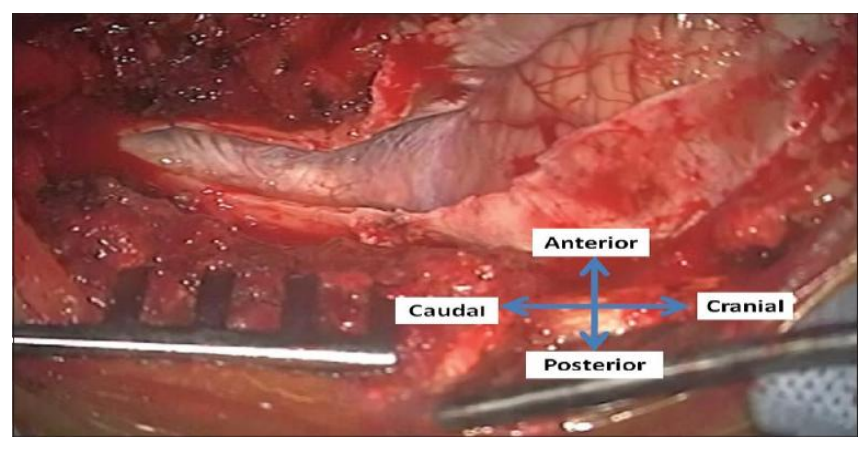

Fig. 4: Dural Opening.

\section{Tumor Resection}

The arachnoid was incised and pushed in a lateral to medial direction. A dural cuff was preserved around the VA. All the various lower cranial nerves and the VA were visualized. In the case of a meningioma, the base was first coagulated and detached and the tumor was debulked using an ultrasonic surgical aspirator. The capsule and rest of the tumor were then removed after freeing it from the adjacent nerves, brainstem and the VA and basilar artery. Total removal was achieved in majority cases with no neurovascular injury. Perfect hemostasis could be easily achieved once total tumor removal was completed (Figure 6).

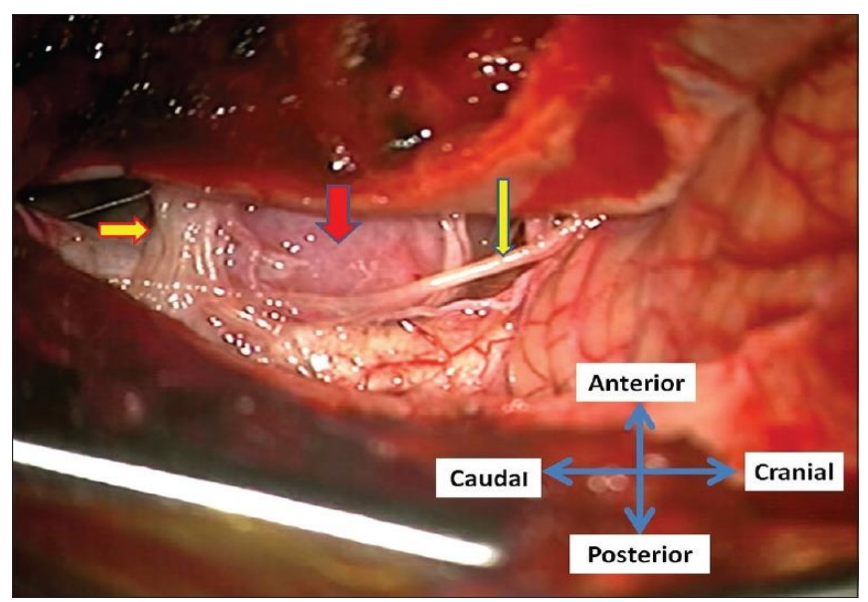

Fig. 5: After opening the arachnoid, the anteriorly placed meningioma (red arrow) is seen. Also seen are the C1 root (thick yellow arrow) and spinal accessory nerve (thin yellow arrow).

\section{Closure}

The dura was closed but not in a watertight fashion. However, it was covered with an autologous fascial graft harvested from the neck and stuck to the dura using fibrin glue. This was further supplemented with 
free fat graft and gel foam. The exposed mastoid air cells once encountered were covered with bone wax. The muscle layers were approximated. Tight fascial layer closure was ensured. We have not resorted to any intrathecal or wound drain.

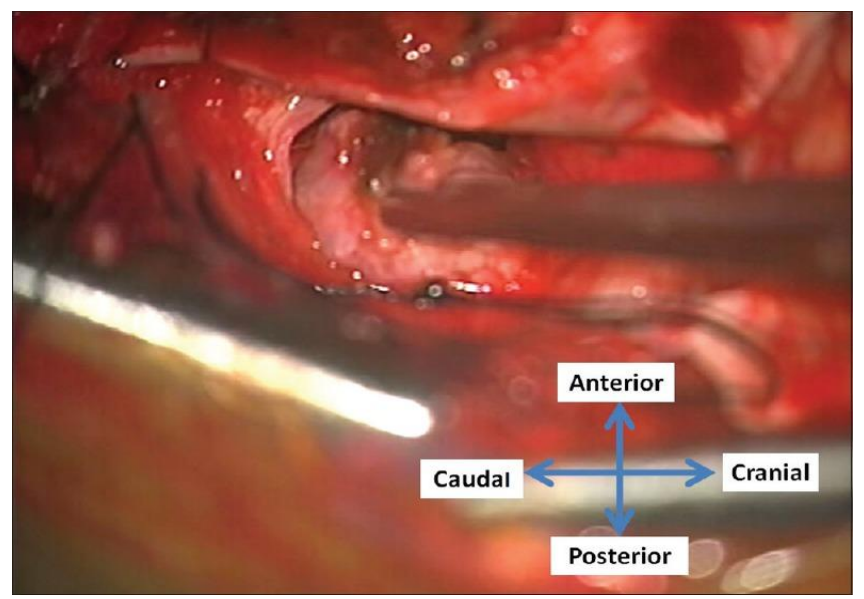

Fig. 6: Tumor being delivered out after debulking with ultrasonic surgical aspirator.

\section{RESULTS}

Demography approach, complication histopathology of 6 patient is shown in Table 1.

\section{Extract of Surgery}

Gross total resection of lesions was achieved in all cases of meningiomas and neurofibromas. Subtotal excision of the clival chordoma was done.

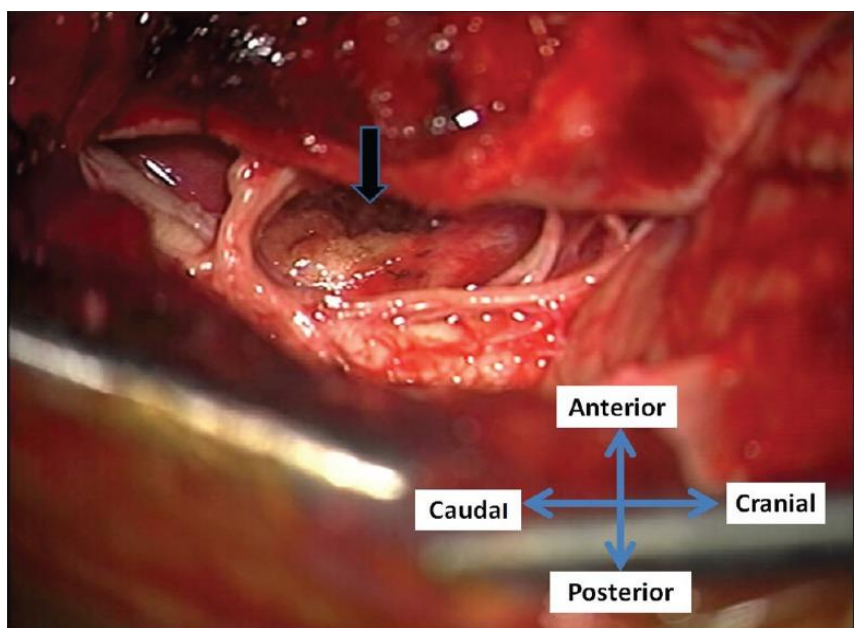

Fig. 7: After total removal of the meningioma. The dural attachment (black arrow) is coagulated.

\section{Complications}

In one patient, a transient cerebrospinal fluid (CSF) leak from wound occurred. The patient was successfully managed by lumbar CSF drainage. No fresh neurological deficits or any other complications were noted in any of the patients.

\section{Outcome}

All patients showed progressive neurological improvement in follow-up visits which was very encouraging.

Three of these lesions were meningiomas, two were neurofibroma and one chordoma. All patients underwent surgery through the far-lateral transcondylar approach complete resection was done

Table 1: Demography, approaches, complications, and pathology of the 6 patients having anterior foramen magnum lesions.

\begin{tabular}{|c|c|c|c|c|c|c|}
\hline $\begin{array}{l}\text { Case } \\
\text { Number }\end{array}$ & Age/Sex & Presentation & $\begin{array}{l}\text { Preoperative } \\
\text { Diagnosis }\end{array}$ & procedure & Complications & Histopathology \\
\hline 1. & $35 /$ male & Neck pain & Neurofibroma & $\begin{array}{l}\text { Far-lateral transcondylar approach } \\
\text { and gross total excision }\end{array}$ & Nil & Neurofibroma \\
\hline 2. & $62 /$ female & Quadriparesis & Meningioma & $\begin{array}{l}\text { Far-lateral transcondylar approach } \\
\text { and gross total excision }\end{array}$ & CSF leak & Meningioma \\
\hline 3. & 42/female & Quadriparesis & Meningioma & $\begin{array}{l}\text { Far-lateral transcondylar approach } \\
\text { and gross total excision }\end{array}$ & Nil & Meningioma \\
\hline 4. & 58/female & Neck pain & Neurofibroma & $\begin{array}{l}\text { Far-lateral transcondylar approach } \\
\text { and gross total excision }\end{array}$ & Nil & Neurofibroma \\
\hline 5. & $48 /$ male & $\begin{array}{l}\text { Bilateral lower } \\
\text { cranial nerve palsy }\end{array}$ & Clival chordoma & $\begin{array}{l}\text { Far-lateral transcondylar approach } \\
\text { and subtotal excision }\end{array}$ & Nil & Chordoma \\
\hline 6. & 30/female & Quadriparesis & Meningioma & $\begin{array}{l}\text { Far-lateral transcondylar approach } \\
\text { and gross total excision }\end{array}$ & Nil & Meningioma \\
\hline
\end{tabular}

CSF - Cerebrospinal fluid 
in five of the neoplastic cases. Subtotal excision was done in the patient with clival chordoma.

\section{Clinical Data}

Two patients presented with neck pain three with progressive quadriparesis one with brain stem compression and bilateral lower cranial nerve palsies. MR imaging with gadolinium contrast was done in all the patients, and a preoperative diagnosis of meningiomas, neurofibromas and clival chordoma were made. All of them were confirmed histopathologically postoperatively.

\section{DISCUSSION}

Anterior foramen magnum pathologies, extending from the clivus to the upper spinal cord, have posed a challenge to neurosurgeons. Excision of these lesions through standard posterior approaches has been fraught with unacceptable morbidity and mortality. ${ }^{4}$ Moreover; total resection is usually not possible with the posterior approach. The far-lateral approach has helped in accessing the anterior and anterolateral corridor and complete excision of this benign lesions. ${ }^{5}$ It provides excellent exposure of the lateral aspect and anterior aspect of the brainstem and upper cervical spinal cord. The use of this approach for clipping of a VA and (PICA) aneurysm has been reported. ${ }^{6}$

The basic far-lateral approach, initially proposed by Heros, is a low suboccipital approach that extends up to condyles but does not include its removal. ${ }^{1-6}$. Moreover, the tumor-brain interface is encountered early during surgery making separation of the neoplasm from the normal structures easier. The other added advantage is the early proximal control of the VA in case of vertebrobasilar aneurysms. ${ }^{7}$ Different nomenclatures for this approach have been used leading to significant confusion. ${ }^{8}$ Various modifications of this approach have been proposed by different authors. Some of these modifications include the following: ${ }^{9}$ The transcondylar approach directed through the occipital condyle, ${ }^{10}$ the supracondylar approach directed above the occipital condyle, and the paracondylar approach directed through the area lateral to the occipital condyle. ${ }^{11}$

Two types of incisions have been described - a posterolateral (horseshoe) flap starting from the ipsilateral mastoid tip and rising upward and curving medially and down to the $\mathrm{C} 3$; a curvilinear retromastoid incision curving anteriorly to the posterior border of the sternocleidomastoid at the level of C4-C5. ${ }^{7-8}$ The muscles are detached as described earlier. The transverse process of the $\mathrm{C} 1$ acts as a landmark to the surgeon in identifying the muscles and preventing VA injury. The far-lateral approach, however, requires a detailed knowledge of the suboccipital muscles since the deeper layer muscles are separated separately.

Knowledge of the suboccipital triangle and the position of the VA in the triangle as well as the common variants of the VA course are essential during the dissection of the extracranial VA. The portion of the VA between $\mathrm{C} 2$ foramen and the superolaterally placed $\mathrm{C} 1$ foramen should be dissected carefully as the VA may form a medial loop in this location. The V3 (horizontal portion of the VA) is encased by a venous plexus and is dissected subperiosteally to prevent any injury to the VA. The muscular and meningeal branches which arise from the VA may be sacrificed, but an uncommon extracranial origin of the PICA if present should be carefully preserved. ${ }^{5-6}$ Some of the authors advocate the transposition of the VA, but we have not found it to be necessary in our experience.

Lateral suboccipital craniectomy or a craniotomy is done. The suboccipital craniectomy should include the entire bulk of the lesion and should extend laterally up to the sigmoid sinus, and inferiorly, the rim of foramen magnum needs to be excised. ${ }^{10} \mathrm{C} 1$ hemilaminectomy is done using drill or rongeurs. This may be extended inferiorly to include $\mathrm{C} 2$ depending on the inferior extent of the lesions. In our series, C2 hemilaminectomy was performed in one case. Drilling the posterior third of the occipital condyle using the high-speed drill is an important step in this approach. Some authors have avoided drilling the condyle, especially in neoplasms which have already displaced the adjacent neurovascular structures.$^{5-6}$ However, we advocate drilling of the occipital condyle in this approach as the angle of visualization is flattened by this step. The importance and utility of this step will be appreciated on opening the dura and reflecting the dural flap anteriorly. This is similar to the drilling of the sphenoid ridge in a pterional approach to make the exposure flat. Drilling the condyle more than $50 \%$ will cause instability necessitating occipito-cervical stabilization. ${ }^{11}$

A curvilinear dural incision helps in reflecting the anterior flap further laterally and increasing the anterior visualization. ${ }^{3-4}$ Superior and inferior extensions of the dural opening are determined by the extent of the lesion. A sharp arachnoid dissection is 
done, and the tumor-brain interface is usually well visualized. We have used an ultrasonic surgical aspirator for tumor debulking. The meningiomas that we encountered in this area were amenable to the usage of the ultrasonic surgical aspirator. The dural attachment was cauterized after total tumor removal. The epidermoids usually do not pose a surgical challenge as they are amenable for suction, especially the "white epidermoids." Adequate precautions to prevent postoperative CSF leakage from the wound should be taken. The far-lateral approach has been modified and extended inferiorly and to excise anterior intradural and some extradural lesions in the cervical spine.

\section{CONCLUSION}

This approach is a very useful to lesions located ventrolateral and even ventral to the foramen magnum, brainstem and upper cervical spinal cord. It provides excellent exposure to the lesion and adjacent neurovascular structures with minimal or no retraction. Various alterations of this approach have been defined and applied depending on the lesion and its extent.

\section{REFERENCES}

1. Babu RP, Sekhar LN, Wright DC. Extreme lateral transcondylar approach: technical improvements and lessons learned. Journal of Neurosurgery, 1994; 81 (1): 49-59.

2. Boulton MR, Cusimano MD. Foramen magnum meningiomas: concepts, classifications, and nuances. Neurosurgical Focus, 2003; 14 (6): 1-8.
3. Bragg TM, Duckworth EA. Contralateral far-lateral approach for clipping of a ruptured vertebral arteryposterior inferior cerebellar artery aneurysm. Neurosurgical Focus, 2008; 25 (6): E9.

4. Husain AKA-MO. M: Ventral foramen magnum meninigiomas. J Neurosurg. 2000; 92 (1): 71-80.

5. Kumar CR, Satyanarayana S, Rao BRM, Palur RS. Extreme lateral approach to ventral and ventrolaterally situated lesions of the lower brainstem and upper cervical cord. Skull Base, 2001; 11 (04): 265-76.

6. Lanzino G, Paolini S, Spetzler RF. Far-lateral approach to the craniocervical junction. Operative Neurosurgery, 2005; 57 (suppl_4): ONS-367-ONS-71.

7. Liu JK, Couldwell WT. Far-lateral transcondylar approach: surgical technique and its application in neurenteric cysts of the cervicomedullary junction: report of two cases. Neurosurgical Focus, 2005; 19 (2): 1-7.

8. Liu JK, Rao G, Schmidt MH, Couldwell WT. Far lateral transcondylar transtubercular approach to lesions of the ventral foramen magnum and craniovertebral junction. Contemporary Neurosurgery, 2007; 29 (10): 1-7.

9. Rhoton Jr A. Far lateral and transcondylar approaches. Neurosurgery, 2007; 61 (S4): 211-28.

10. Sharma B, Gupta S, Khosla V, Mathuriya S, Khandelwal N, Pathak A, et al. Midline and far lateral approaches to foramen magnum lesions. Neurology India, 1999; 47 (4): 268.

11. Wen HT, Rhoton AL, Katsuta T, de Oliveira E. Microsurgical anatomy of the transcondylar, supracondylar, and paracondylar extensions of the farlateral approach. Journal of neurosurgery, 1997; 87 (4): $555-85$.

\section{Additional Information}

Disclosures: Authors report no conflict of interest.

Ethical Review Board Approval: The study was conformed to the ethical review board requirements.

Human Subjects: Consent was obtained by all patients/participants in this study.

Conflicts of Interest:

In compliance with the ICMJE uniform disclosure form, all authors declare the following:

Financial Relationships: All authors have declared that they have no financial relationships at present or within the previous three years with any organizations that might have an interest in the submitted work.

Other Relationships: All authors have declared that there are no other relationships or activities that could appear to have influenced the submitted work.

Address for Correspondence:

Waqas Mehdi

Neurosurgery department, Mayo Hospital, Lahore

Email: drwaqasmehdi@gmail.com 


\section{AUTHORSHIP AND CONTRIBUTION DECLARATION}

\begin{tabular}{|c|c|c|}
\hline Sr.\# & Author's Full Name & Intellectual/Contribution to Paper in Terms of: \\
\hline 1. & Waqas Mehdi & 1. Main investigator/ data collection. \\
\hline 2. & Azam Niaz & 2. Data analysis and report writing \\
\hline 3. & Muhammad Irfan & 3. Data Collection \\
\hline 4. & Shahzaib Tasdique & 4. Co investigator \\
\hline 5. & Samra Majeed & 5. Literature review \\
\hline
\end{tabular}

Date of Submission: 05-4-2020

Date of Revision: 23-06-2020

Date of Online Publishing: 30-06-2020

Date of Print: 30-07-2020 